\title{
Forecasting USTourists' inflow to Slovenia by modified Holt-Winters Damped model: A case in the Tourism industry logistic s and supply chains
}

\author{
Dejan Dragan ${ }^{1}$, Abolfa zl Keshava rzsa leh², Tomaž Kramberger ${ }^{1}$, Borut J ereb1, Maja Rosi ${ }^{1}$ \\ 1 University of Maribor/Fa culty of Logistics, Celje, Slovenia \\ 2 University of Malaya (UM) and Intemationa I University of Malaya-Wa les (IUMW), Kuala Lumpur, \\ Malaysia
}

\begin{abstract}
Forecasting is important in many branches of logistics, including the logistics related to Tourism supply chains. With an increasing inflow of American tourists, planning and forecasting the US tourists' inflow to Slovenia have gained far more importance attention amongst scholars and practitioners. This study, therefore, was conducted to forecast the American tourists inflow to Slovenia using one of the predictive models based on the exponential smoothing approach, namely Holt-Winters damped additive (HMDA) exponential smoothing method. The model was modified by several improvements, while the obtained results were generalized to other supply chain components. The results show that the forecasting system can predict well the obsenved inflow, while the methodology used to derive the model might have enriched the plethora of existing practical forecasting approaches in the tourism domain. Benchmarking demonstrates that the proposed model outperforms a competitive ARIMA model and official forecasts. The practical implications are also disc ussed in this paper.
\end{abstract}

Key words- Tourism industry logistics and supply chains, Tourism forecasting, US tourists and Slovenian Tourism, Damped Holt-Winters additive model, Time series analysis and prediction.

\section{INTRODUCTION}

The United States are an important global player in the world wide tourism industry; not only have many tourists traveled to the United States but also many tourists from the United States make a joumey to other countries. Indeed, advancements in Information Technology, mass media, transportation infrastructure along with globalization create both interconnected worldwide economic ecosystems and interlinked nexus of tourists who are being driven by many driving factors to choose the next destination. For example, tourists are drawn to Slovenia for its natural, cultural and historical attractions. A promotional Slovenian tourism destination identity campaign, so-called "I feel Slovenia" in April 2016 []ㅡ has proven to be substantially suc cessful in its mission. As a consequence, the Slovenian tourism industry started to boost up.

As globalization takes place, periodic al socio-political altemates on the other side of the globe may lead to implicit or explic it progress or regress of another nation which is located on a nother continent. For example, two years ago, Melanie Trump has become a first "first lady" in the US with roots from Slovenia. Ever since then, perhaps completely coincidentally, already inc rea sing ly ac celera ted-growth of visits of Americ an tourists has been even multiplied, presuma bly also due to Melanie's popularity among the American people. Whether this progression in Slovenia's truism inflow is implic itly or explicitly linked to Melanie Trump or no, is beyond this study's scope. However, the significance of planning and forecasting within Slovenia' tourism context due to the inc reasing growth of US tourists need to be substantially a ddressed.

The proper planning and forecasting of the tourists' inflow in a tourism supply cha in are of the utmost importance research area. The higher the number of the tourists inflow, the more precise the planning and forecasting ought to be. Indeed, an ineffective tourism supply chain today will lead to various losses tomorrow [2]. Tomorrow's losses might not only be appeared as a loss in revenue but also might be seen as the worst types of losses ever such as the emergence of 
inefficient tourism products/services and a damaged destination identity. The tourism industry is a complex industry; thereby, there are many factors and indicators linked to its supply chain components which cannot be simply ignored. To avoid, there is a need for being proactively productive when it comes to planning and forecasting.

This paper as a forecasting study aims at highlighting the importance of the role of inc reasing influx of US tourists into Slovenia. Perhaps the role of Slovenian first lady is a lso essentially important for such increased influx if presumed on the basis of different official and unofficial sources. However, unfortunately, the fact is that no quantitative study (e.g., grounded on a questionnaire-based survey a mong the US tourists in Slovenia) has been conducted yet until now to identify the main reasons for the coming of US tourists into Slovenia. In any case, we should put the spotlight on the fact that the official expectations about the future tourists' a mivals from the US might be signific antly underestimated if the role of Slovenian first la dy would be truly confimed, but dec eitfully neglected.

This study was conducted to forecast the American tourists' inflow to Slovenia using one of the predictive models based on the exponential smoothing, i.e., the Holt-Winters Damped Additive (HMDA) exponential smoothing model [3]. The model was modified by several improvements, while the obtained results were generalized to other supply chain components. This way, our study uniquely deployed a composed modeling framework in regard to forecasting through modeling design heuristic procedure prior to testing and validating the model. It is argued that the findings of the study can be used by practitioners and scholars who are interested in the application of forecasting within specific countries' tourism ind ustry context.

\section{THE TOURISM INDUSTRY IN SLOVENIA AND THE FORECASTING CONTEXT OF THE STUDY}

\section{A. Cha racteristic of Slovenian tourism}

Tourism is known to be an important economic activity globally due to its direct and ind irect economic impacts. To elaborate, the direct economic impacts can be seen as any impacts on commodities, and tourism sub-industrial sectors while the indirect economic impacts can be seen as travel and tourism investment spending and the emergence of public-private partnership projects which are pertinent to tourism infrastructure and service ecosystem. Slovenia due to its strategic geographical location has always been seen as a great destination for tounists, partic ularly in the areas such as transit tourism, winter sport and, summer sea side vacations $[\underline{4}, \underline{5}]$. Tourism in Slovenia is at the pivotal point of its history [1].

The tourism industry in Slovenia has gone through many modific ations as times go by, more importantly, privatization. It is argued that this country although it is mature in tourism product development, it lacks a service culture. The privatization of the industry has positively contributed to the nations' economy because private ownership performed much better regarding susta ina bility, intema tiona lization, marketing strateg ies and, tounism product development [6-8].

\section{B. The role of Americ an tourists in Slovenia}

The final fruit of all above-said efforts has led to attracting many tourists from all a round the world, especially from the United States, particularly for the reason that they are on average the best consumers spending a lot of money. With an increa sing number of Americ an tourists' inflow to Slovenia over the past two decades, this study conducted an improved exponential smoothing model for forecasting of the United States tounists' inflow to Slovenia.

During the last few years, presumably also due to the fact, that the US has for the first time got a Slovenian first lady, the increase in a mivals of US tourists is even much more significant. This fact has been most likely caused by the fact that Slovenia has become widely recognized in the eyes of many US citizens. Also, the tourists who have already been in Slovenia non-stop spread a good opinion about this country all over America.

This increasing tourists' inflow has led to a continuous research effort regarding the tourism industry in Slovenia and its tourism supply chain specific ations. Since the launch of "I feel Slovenia" in which the country's tourism has set to be a beaten heart of Slovenia's identity, the Slovenian tourism industry has gained a tremendous boost [1]. Although it is boosting up as time goes by, 
intensified competitions have impeded the progress towards reaching the tourism-led economic growth competitiveness. The competitiveness cannot be obtained ovemight; thereby, planning and forecasting are golden keys to the future success of the Slovenian tourism ind ustry.

\section{The proposed forecasting approach}

Having this in mind as the spotlight of our study, we feel responsible to contribute back to this sector through deploying and yielding the current practical forecasting modeling approaches within the tourism sector in Slovenia. To do so, the US tourists' inflow historic al cumula tive time series data to Slovenia[9] have been analyzed and predicted by using the well-known HWDA exponential smoothing model $[\underline{3}, \underline{10}]$ that was carefully investigated and improved with a special heuristic.

The standard Holt-Winters (HW) method can handle the time series with the trend, level, and a single cycle (i.e., the sea sonal pattem). According to $[\underline{3}, \underline{11}]$, Taylor has in his three works $[\underline{10}, \underline{12}$, 13] developed a multiple cycle version of Holt-Winters model, which is able to deal with the time series with longer forecasting horizons and multiple cycles. Since then, with the exception of work [11], at least to the best of our knowledge, practically none research can be found that would make some further relevant improvements regarding the HWDA model.

Thus, we believe that in this paper, after more than a decade, some essential enhancements have been conducted with respect to the basic version of HWDA model. Some of the ideas for these improvements have been initiated due to inspiration from some of our previous studies [14-16]. At this place, it must be emphasized that the described modeling approach for the HWDA model is generic, which means that at least in principle, it might have been used for any similar type of forec asting in a ny industry, as well as in a ny country or c luster of c ountries.

D. Possible contributions

It is argued that this study contributes to knowledge and practice in the following ways:

(a) After a longer time period of existence of the classical HWDA model, some essential enhancements have been conducted with respect to the basic version of HWDA model,

(b) The model is proven to be more or less effective for the case of the observed country. However, it could also be generalized to cover other supply chain members within a certa in industry or industries in general irrespective of their size, type, and location. The latter means that a presented model could be due to its generalization conducted for any similar types of forecasting (e.g., the demand forecasting, sales forecasting, road freight transport forecasting, etc.).

(c) There are practically no similar studies identified in the tourism management context, introducing a specially composed modeling framework for the forecasting considering the proposed modeling design heuristic procedure,

(d) The proposed approach possesses a broad spectrum of the different rigorous criteria for model testing and validation that can ra rely be found in other comparable studies, and

(e) Surprisingly, to the best of our knowledge, there were practically none studies detected that would systematically analyze the predictive models in any context regarding the tourism industry in Slovenia.

The derived model was identified within the quarterly based time interval (2003-2016). Afterward, during the benchmarking, the forecasts of our model have been compared with the real data from different sources (the actual data obtained from different tourism facilities), as well as with the competitive ARIMA model and the official forecasts for the year 2017 (such as from Slovenian Statistical Department (SSD) and Department for Macroeconomic Analyses and Development (DMAD)). Surprisingly, our model has on average significantly outperformed ARIMA model and official forecasts for 2017 (app. 85.000 US tourists) and approached much closer to the value of the real data (on a verage about 101.000 tourists). 


\section{E. Main motives for research}

There have been two major motives for conducting this study. The first one was conceptual and related to the improved methodology regarding the modeling design of the conducted predictive model. The second one was applicative since we wanted to investigate to what extent the official forecasts are reliable and trustworthy regarding US tourists. Namely, the Slovenian Tourism is very important for the country economy since it represents about $13 \%$ of the total GDP.

Thus, any unreliable forecasts regarding any important aspect within the tourism industry can lead to inappropriate planning of future strategic al-level tourism-related polic ies. These facts should also be considered for the forec asting of future inflows of important groups of to unists (from the most relevant countries). Since the US tourists play a more and more important role as "generouslyspending" customers, the accuracy in forecasting is quite important, while significant misc alc ula tions from the official institutions should have been strictly forbid den.

Furthemore, our suspic ion about the credibility of forecasts of official institutions was grounded on the facts that in the recent past, the official institutions have already made many serious erroneous forecasts about pretty important things, such as inadequate forecasting regarding the GDP, the future liquidity of Slovenian banks and fims, and so on. These mistakes have sometimes caused millions or even dozens of millions of Euros of unnec essa ry losses.

Presumably, our model has much more accurately recognized a possible impact that popularity of Melanie Trump has had on an increased inflow of US tourists than it was detected by Slovenian offic ial institutions. Natura lly, maybe there a re also some other additional rea sons for such unusually enormous rise of the US tourists' inflow in just one observed year (from the end of 2016 to the end of 2017).

These reasons might be perhaps related to a good state of US economics' indicators including the increased Consumption Price Index, or the global rise of the tourists' visits worldwide. Yet, it is still unusual that even a $\mathbf{1 9 . 8 \%}$ increase in tourists happens in just one year. Namely, if we denote a time-dependent inflow with a symbol $y(t)$, we are dealing with the situation: $y(2016 Q 4)=81000 \rightarrow y(2017 Q 4)=101000 \rightarrow 19.8 \%$ increase of US tourists in only one year!

Also, before Trump was elected for the US president, Melanie's hometown called Sevnica was just an average boring small town. Conversely, after his election, in just a couple of years, it has transformed into an important modem touristic spot. Even more, according to the official records (e.g., SSD: https://www.stat.si/StatWeb/Field/Index/24), the huge tourists' inflow increase has happened in Sevnic a, while the majority of new visitors have been Americans!

\section{LITERATURE REVIEW}

\section{A. The importance of the tourism ind ustry for national ec onomies}

The tourism industry is arguably known as one of the main contributors to the countries' national economy. Since introduction of the Tourism and Travel Competitiveness Index (TTCI) by World Economic Forum (WEF) back in 2015, two criteria have been set to be significant in measuring the $\mathrm{TCCl}$ [17]; (a) quality of tourism supply/value chain and (b) characteristics of the destination country in itself. It was in this context that the competition occurred, emphasizing on infrastructure, cultural and natural resources indicators of the $\mathrm{TTCl}$, for example, transportation infrastructure, tourism service providing ecosystem, cultural and sports attractions, and world heritage properties [18].

This revolutionary trend, namely Tourism-led Economic growth triggered a heated debate between the scholars whether the relationship between tourism and economic growth is bidirectional and interactive, if so, whether the previous research results are non-conflicting and consistent or no. An in-depth review of previous literature can be divided into two strands; relooking to this concept from a holistic and detailed-oriented point of view. To elaborate some of the holistic-oriented studies, for example, an empinical study conducted in Spain revealed that 
there are a unidirectional cause and effect relationships between tourism and economic growth [19]. In addition, a study was conducted in 2003 in which 13 OECD countries were investigated [20]; the results revealed that tourism and economic growth are positively interconnected. Moreover, a nother study conducted in Uruguay unc overed a relational attribution of to urism costs on GDP per capita [21]. Dritsakis in 2012 conducted a study covering seven Mediterranean countries. Results of the study provided a solid confimation on the positive effects of to urism on GDP [22].

It seems that there is a firm consensus among scholars regarding the positive impacts of to urism on nations' ec onomy a cross 55 various countries [23]. To briefly mention, studies conduc ted in Turkey [24], Tunisia [225], southem European countries [266], Singapore [27] and South Africa [28] have also shown the same results. However, scholars who used the detailed-oriented perspectives put the emphasis on the role of sub-industries in tourism supply cha in and tourism economic growth networks at the sub-industrial level such as tra vel a gents, hotels a nd a irlines [29-32]. Therefore, it can be concluded that planning the infrastructure and deploying the forecasting models in any destination countries will pay off; however, there is a need to put more efforts on the models' effic iency, concomitantly to consider the inc lusion of extemal exogenous effects as well.

\section{B. Planning the infrastructure and the significa ance of forecasting in tourism}

Competitiveness in tourism has its roots in numerous indic ators such as destination country's economy, tourism sector infrastructure, tourists' income level, and other economic and political indic ators such as buying power, currency rates, social openness, religious and culture, etc. Tourism industry is a complex industry sector that needs to be considered a s monolithic block in which its all supply chain components are matter, particularly the tourism infrastructure. It can be said that there is a robust relationship between tourism development and infra structure [33].

The infrastructure base of each country can be seen as a determinant of that country's tounism destination attractiveness. Therefore, planning the infrastructure and the signific ance of forecasting in tourism industry context cannot be ignored anymore. Since the performance of the tourism sector is highly tied to socio-political factors [34], infrastruc ture development [35], immigration and visa policies [36], and political events [37]; thereby, there is a need for properforec asting.

The forecasting in tourism research spheres has been highlighted in the previous literature extensively. For example, in regards to destinations' future tourism demand forecasting, many economic factors are considered including both macroeconomic factors and microeconomic ones [38, 39]. Therefore, it can be asserted that in order to obta in effective planning, the necessity of forecasting in tourism need to be intensified.

\section{Forecasting approaches in the tourism industry}

Forecasting has seen to be beneficial when it comes to the development and investment planning in tourism [40] as well as to demand fluctuation of tourism inflow [41]. There are many studies which deployed various types of forecasting models in tourism inflow forecasting and its other often-related areas. For example, a study conducted by Cho in 2003 aimed at forecasting tounists' a mivals in Hong Kong in which three predictive models were comparatively investigated [느]. Findings of the study revealed that ANN (artificial neural networks) is the most accurate one comparing to Univariate ARIMA and the exponential smoothing method.

Forecasting tourism a mival in Singapore was conducted by the Chu in 2008 in which the fractionally integrated ARIMA models were investigated and ultimately comparatively compared with the traditional ARIMA models [43]. In a nother study, which was conducted by the same author in 2011 considering Macau as a destination, fractionally integrated ARIMA models, seasonal ARIMA and a piecewise linear model were investigated [44]. The findings of the study introduced a piecewise linear model as the most effective and accurate among others.

The new forecasting model, namely TVP-STSM was developed in a study conducted by Song \& Collogues in order to both model and forecast quarterly Chinese, Korean, British and American to urist a mivals to Hong Kong [45]. The empirical results, according to the authors, indicate that the proposed combination of TVP (time-varying parameter) and STSM (structural time series model) works appropria tely compared to related tra ditional ones. 
Regarding U.S tourist a mivals, SSA (Singular Spectrum Analysis) using monthly data for tourists inflow to the U.S between the period 1996 and 2012 were investigated in a study conducted by [46]. The results of their study concluded as SSA can be an accurate approach for forecasting tourism demand and it worth to deploy in similarcases.

It can be said that there have been too many forecasting techniques so far. To categorize, quantitative forecasting models which have been developed so far can be seen as Artificial Intelligence-based, time series models and the econometric methodical approaches. Time series models which are dependent to previous data in the series to forecast the future trends, can be divided to some sub-clusters including; SMA (Simple Moving Average), Navi, SES (Single Exponential Smoothing), DES (double exponential smoothing), ARIMA (autoregressive moving average) and BSM (basic structural time series).

Although they are proven to be effective forecasting models when it comes to forecasting tourism inflow, they are substantially limited to non-economic factors [47]. This means the significance of tourists' behavioral attributions is not configured in these models. Some scholar, therefore, argued that the econometric models are performing better, assisting policymakers in assessing the effectiveness of the policies and strategies deployed [48].

An in-depth review of the literature indicates that there is various way to forecast tourism demand/inflow or other often-related areas. Some models outweigh others in some cases, depending on various indicators either endogenous or exogenous. For example, the standard ARIMA a ims at forecasting according to the past values of the forecast va riable while its extended version, known as $A R M A(X)$ includes a nother predic tor (independent) va ria bles in order to enhance the accuracy of a forecast in itself.

The $\operatorname{ARIMA}(X)$ is deployed in many studies such as forecasting Turkey's tourism-led revenue [49] forecasting the intemational tourism demand in Japan [50] and so on. Moreover, Holt-Winters damped additive exponential smoothing model could have positioned itself among other forecasting models due to its robustness and enhanced accuracy. This approach deployed in many studies which address long-lead times such as long-lead time forecasting of UK air passengers [51] forecasting the intemational tourist a mivals to New Zealand and Australia from 11 destinations [52] monthly volume of tourism inflow into Bulgaria [53] etc.

Somehow, to complement the literature, in this study we aim at introducing our forecasting technique as some counterpart competitive approach to other more common forecasting approaches and screen it aga inst other models. Slovenia is considered as the targeted destination country in this study due to its emergent tourism industry which it attracts many tourists from all around the globe, more importantly, from the U.S. Regarding our modified HWDA forecasting model, contrariwise to its basic version, a number of criteria must be considered such as; (a) the chosen model must be able to provide an accurate forecasting according to forecast the direction on any possible changes occurred and (b) last but not the least, the chosen forecasting model must be able to consider short-run and long-run intervals.

\section{THE HISTORICAL DATA}

\section{A. The historical data for US tounists' inflow to Slovenia}

Slovenia has been the destination of many tourists as time goes. The Americans are not an exception, and more importantly, besides the most essential visitors from the EU, they are considered the most signific ant contributors to the Slovenian tourism industry. Indeed, America is categorized as the distant marketplace for Slovenians and vice versa [54]. Recently, Slovenia expanded and intensified its promotional tourism destination campaign in the USA.

Maja Pak, the Director of the Slovenian Tourist Board, indicated that the media's interest and the publicity have been a great advantage in order to intensify the Slovenian tourism destination promotional campaigns. At the second quarter of 2016, Slovenia was the designation of 78209 American guests. Compared to the second last quarter of 2015 when Slovenia was visited by 70488 Americ an guests, there is an increase of 10.9 percent. 


\section{Logistic $s \&$ Susta ina ble Transp ort \\ Vol. 10, No. 1, J une 2019, 11-30 \\ doi: 10.2478/jlst-2019-0002}

According to the estimation which was made by the Director of the Slovenian Tourist Board, 2017 has been a witness of 5 to 6 percent increa se in Americ an guests' a miva ls; statistic a lly, from the end of 2016 which the numbers of guests were about 81167 to about 85000 at the end of the year 2017.

Simulta neously, similar estimates (about 85000) have been made from some other govemment institutions (SSD, DMAD). According to the govemmental reports, the capital city of Ljubljana has been witnessing of many visitors as well. Interestingly, the American tourists were ranked in a fourth high spot regarding the ovemight stay's sta tistic s just before visitors from UK, Gemany, a nd Italy.

For the guests from the USA, it is also evident that they conduct on an average far biggest number of ovemight stays compared to the tourists from the other distant markets. They also hold the primate about spending the biggest a mount of money for direct tourism-related expenses, as well as different indirect expenses (among all tourists in Slovenia as a whole!). Fig. 1 shows a rough estimate of US tourist a mivals, and comparison to their ovemight sta ys for yea rs 2006-2015 [55, $\underline{56]}$.

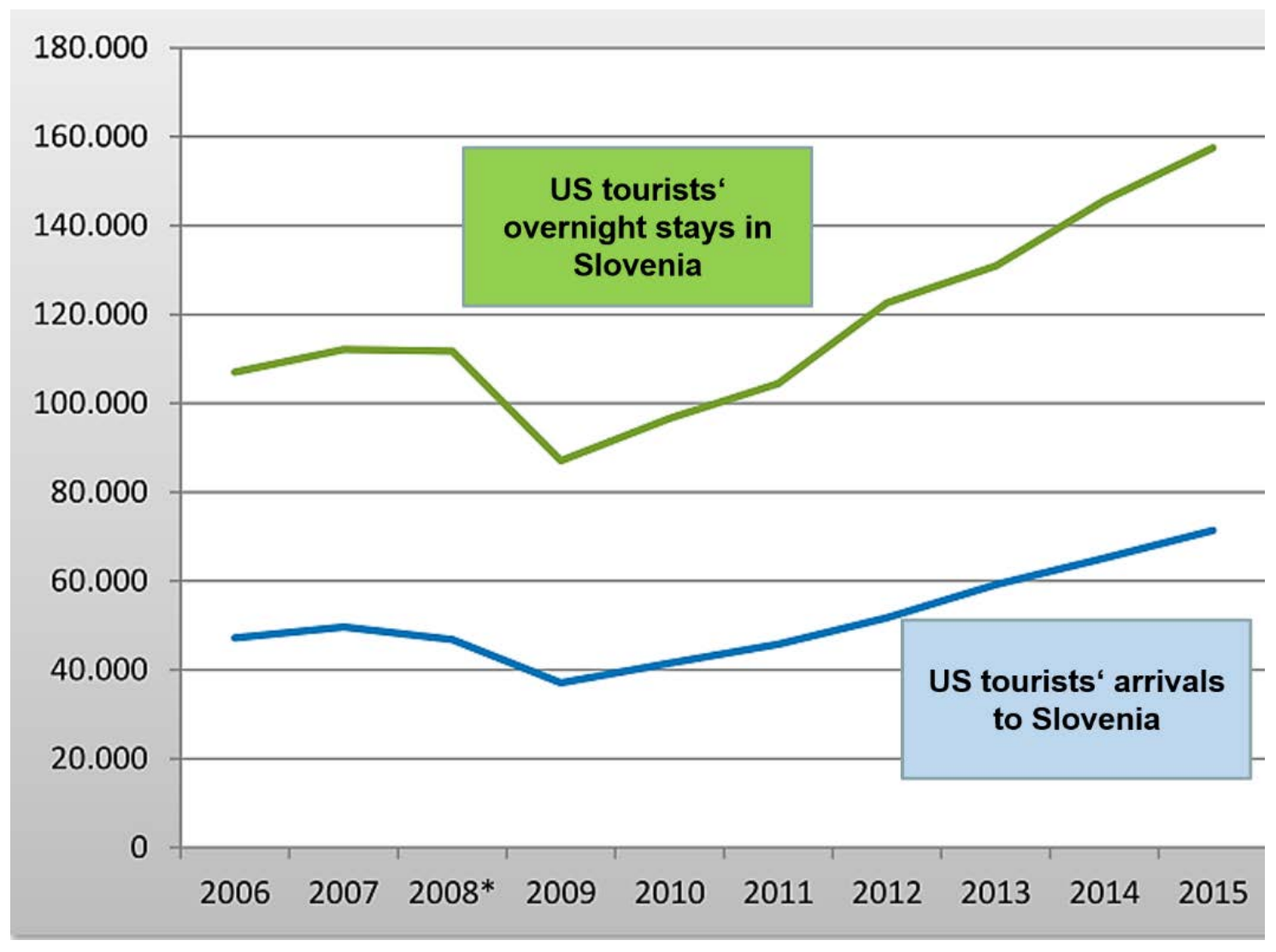

Figure 1. US to unist a mivals and comparison to their ovemight stay for years 2006-2015.

Fig. 2 illustrates the quarterly cumulative inflow of US tourists between 2006 and 2016 (SSD: https://www.stat.si/StatWeb/Field/Index/24). As can be seen, both volumes of amivals and ovemights stay in Slovenia has been growing gradually, except a sharp plunge in both volumes of a rivals and ovemights stay in Slovenia 2009 due to the enuption of the economic crisis in 2008. However, later it has captured a steady increasing trend again. For the years 2013 to 2016, the inflow has reached cumulative values (at the end of the fourth quarter): 60224, 66004, 74759, and 81167 tourists, respectively, thus percentage increases in values: $9.5 \%, 13.26 \%$, and $8.5 \%$, respectively. The time series shown in Fig. 2 is also the targeted output variable $y(t)$, for which we want to design our forecasting models. 


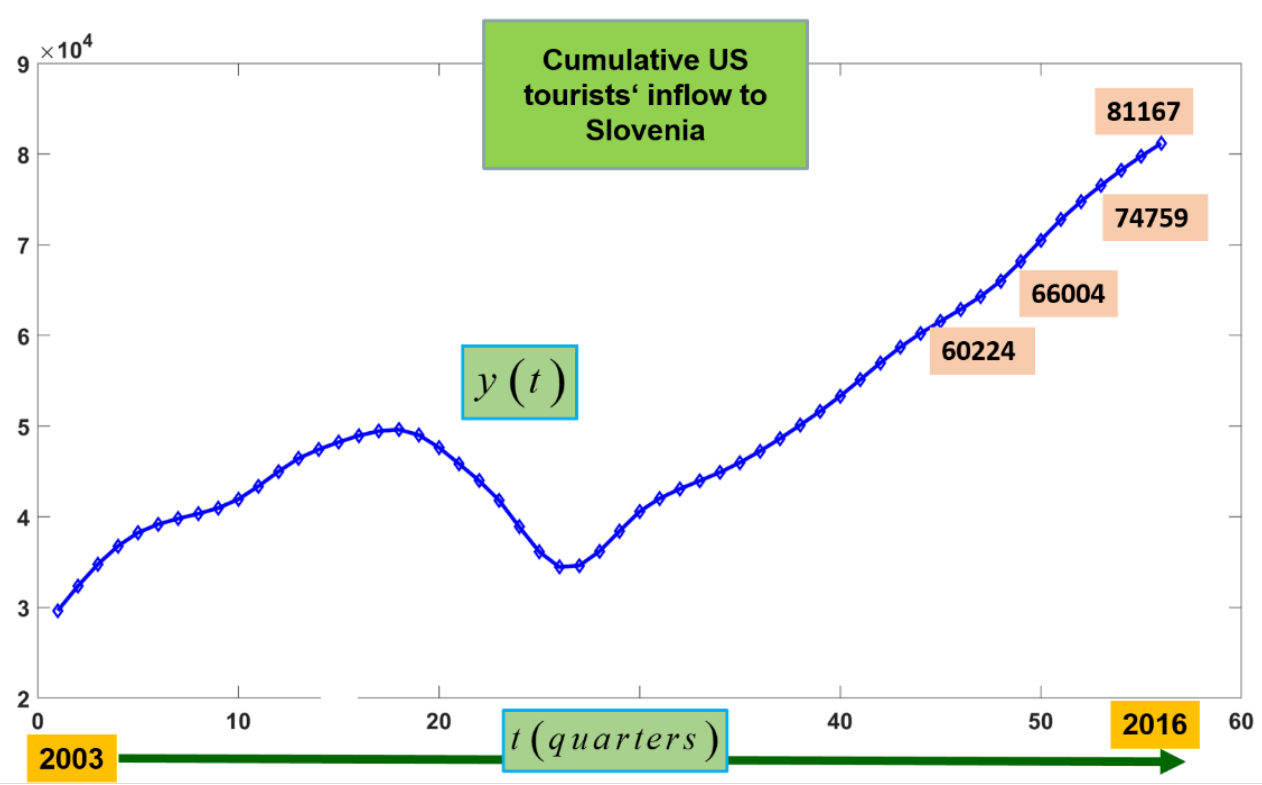

Figure 2 . The time series data of quarterly cumula tive inflow of US tourists in the time-period (20032016: $t=1,2, \ldots, N=56$ qua rters).

\section{METHODOLOGY FOR A FORECASTING MODEL}

A. The conceptual modeling framework

Fig. 3 illustrates a conceptual modeling framework for our research. In block B, we can see the available collected data for the tourists' inflow time series $y(t)$ that represent a basis for the whole research. Block C refers to the basic version of a treated HWDA model, whose output $\hat{y}(t)$ is preferred to closely follow the time series $y(t)$ disturbed with the random noise $\varepsilon(t)=\varepsilon_{y}(t)$.

In the modeling process, the basic model enters into the main advanced heuristic framework (block D, stage 1), which is optimized in such a way that can process thousands of model candidates in an acceptable amount of computation time. Further, for a HWDA structure that is always fixed, a wide set of possible parameter sets is settled, from where a different parameter set is assigned to each model candidate in each iteration $\mathrm{j}$ of the procedure (block $\mathrm{E}$, stage 2). In the third stage (block F), the diagnostic checking is conducted, and goodness of fit (GOF) measures are calculated for each model candidate. Here, partic ularly important is a model candidate's error $e(t, j)=y(t)-\hat{y}(t, j)$ that is different in each iteration $\mathrm{j}$ depending on the specific calculated model's output $\hat{y}(t, j)$.

A special sub-heuristic is developed during the model selection process which is employed in the fourth stage (block $\mathrm{G}$ ) in order to obtain and find the best model companing to many other model candidates. To do so, different pre-defined rules and statistical ones for each candidate have also been deployed. Such heuristic gives us the final most adequate HWDA model, which can be considered as the best one. Further, besides providing the well model's fit to the real data $y(t)$, the final obtained model satiffies all other rigorous mathematical and statistical conditions, particularly those related to the residual-based criteria. This way, when the modeling procedure is ended, we obtain the best model with a corresponding output: $\hat{y}\left(t, j^{*}\right)=\hat{y}_{H W D A}\left(t, j^{*}\right)=\hat{y}^{*}, j^{*}$-iteration with best criteria fulfilled, for which the optimal error $e^{*}=y-\hat{y}^{*}$ can be obtained (block H in Fig. 3)). Afterward, we can analyze the forecasting 
performance of the best model's output $\hat{y}^{*}(t)$ on the basis of different model-error based criteria (block I).

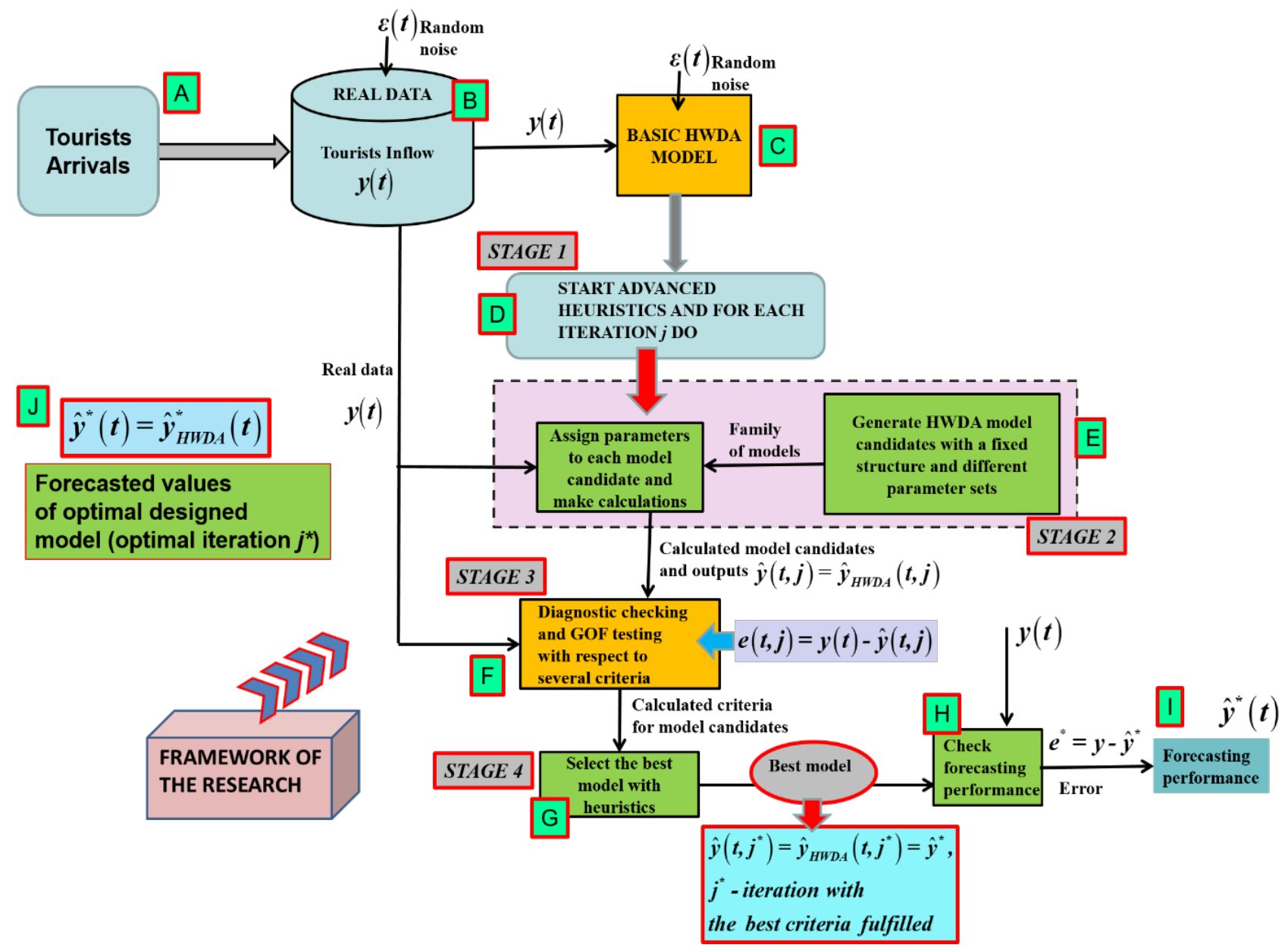

Figure 3. A conceptual modeling framework of the research and a conducted HWDA-based dec ision support system forec aster (DSSF).

B. Basic Holt-Winters da mped additive exponential smoothing model (HWDA)

In general, exponential smoothing (ES) methods refer to a special class of forec asting methods. [3]. There exist a whole plethora of methods that belong to the exponential smoothing class of methods. Their major property is that forecasts are weighted combinations of past observations, with more recent measurements being relatively more weighted than the older ones. The title "exponential smoothing" implies the fact that the weights decline exponentially as the mea surements get older [57].

Generally, we are dealing with three basic types of ES methods, i.e., the single ES (Brown's method), the double ES (Holt's method), and the triple ES (Holt-Winters method). The latter is suitable when we presume some evident trend and seasonality in the observed time series [됴]. According to the empirical evidence, the basic Holt-Winters method has a tendency to make overor-under forec asts, partic ula rly for longer forec asting horizons [59-61]. For this reason, Ga rdner a nd McKenzie (1989) have applied a new parameter $\varphi$ associated to the trend component that dampens the trend to a flat line, when the future becomes more distant. This way, we can obtain the Holt-Winters damped additive method (HWDA) in the following form with four parameters $\alpha, \beta, \gamma, \phi$ [57]: 
Level : $\quad \ell(t)=\alpha \cdot(y(t)-s(t-m))+(1-\alpha) \cdot[\ell(t-1)+\phi \cdot b(t-1)]$

Growth: $\quad b(t)=\beta \cdot[\ell(t)-\ell(t-1)]+(1-\beta) \cdot \phi \cdot b(t-1)$

Seasonality: $s(t)=\gamma \cdot(y(t)-l(t-1)-\phi \cdot b(t-1))+(1-\gamma) \cdot s(t-m)$

Forecast: $\quad \hat{y}(t+h \mid t)=\ell(t)+\phi_{h} \cdot b(t)+s\left(t-m+h_{m}^{+}\right)$,

where: $\phi_{h}=\phi+\phi^{2}+\ldots+\phi^{h}, h_{m}^{+}=[(h-1) \bmod m]+1, m-$ number of seasons |year

$h$-time points of the future horizon

Conversely to the other exponential smoothing methods that can be linked with a linear BoxJ enkins methodology and state space approach, the HWDA is nonlinear in its nature [3]].

\section{A brief discussion of the advanced heuristics conducted in the modeling mechanism}

Modeling mechanisms related to the HWDA model were extensively explained in some of the previously conducted studies [14-16]. However, the corresponding heuristics were in previously conducted researches implemented inside the wider structure of the so-called DFM-ARIMAX model (ARIMAX model, whose inputs were the dynamic factors from the dynamic factor analysis). Moreover, since then, many additional novelties have been engaged in this research.

If we carefully observe Fig. 3 and the description of an HDWA model in the previous section, we can see that the HWDA model has a fixed structure with four parameters $\alpha, \beta, \gamma, \phi$ (see (1)). If we are generating a family of HWDA models by changing the sets of parameters $\alpha, \beta, \gamma, \phi \in[0+\varepsilon, \Delta j, 2 \Delta j \ldots, 1-\varepsilon], \Delta j \rightarrow 0, \varepsilon \rightarrow 0$, we can obta in a huge group of model candidates.

The more in detail illustrated working mechanism of an applied heuristic for stages 3 and 4 from Fig. 3 is shown in Fig. 4. Ascan be seen from Fig. 4, three types of tests were first calc ulated at each iteration of the procedure for each model candidate. Stage 3 has covered the computation of different statistical tests, the residual-based tests (for model's emor $e \rightarrow e_{j}(t)=y(t)-\hat{y}_{j}(t), j$-th iteration), and the future dynamics' tests (checking of the future out-of-sample (FOS) forec asts: $\left|\hat{y}_{j}(t+h)\right| \leq$ thresholds?, $h-$ FOS horizon ).

Also, the model's emor of each candidate was carefully investigated to check whether it holds approximate properties of the nomal white noise or no. Immediate exclusion of candidates with inadequate future responses, i.e., $\left|\hat{y}_{j}(t+h)\right|>>$ thresholds was needed to avoid unusual or impossible future situations compared to the past trend's dynamics of $y(t)$. We have also applied so-called Dynamic Time Warping (DTW) giving a DTW value $[\underline{62}, \underline{63}]$ that have measured the "distance" between two signals $y(t), \hat{y}_{j}(t)$ by using the Kullback-Leibler distance: $d\left[y, \hat{y}_{j}\right]=\sum_{t=1}^{N}\left[y(t)-\hat{y}_{j}(t)\right] \cdot\left[\log y(t)-\log \hat{y}_{j}(t)\right]$. The testing of DTW values for different candidates was essentially important since it has in a refined way detemined how truly "far" among each other are the signals $y(t), \hat{y}_{j}(t)$ [63] .

Let us emphasize that the calculations in stage 3 , as well as a reducing procedure for excluding of inappropriate candidates in stage 4 , were camied out by very sophistic ated heuristic s ba sed on the sequence of carefully designed consecutive steps. This way, despite the significantly enomous amount of model candidates, the whole model selection procedure to find the best model candidate was executed in a reasonable computational time. A demand for simultaneously fulfilled all relevant tests in stage 4 was so strict that only a few candidates remained in the reduced set. In the final step, the best candidate was chosen according to the best \%FIT, i.e., the best fit: 
$\hat{y}_{j}(t)_{\text {best }}=\hat{y}\left(t, j^{*}\right)=\hat{y}_{\text {HWDA }}\left(t, j^{*}\right)=\hat{y}^{*}\left(j^{*}\right.$-iteration with the best criteria fulfilled $) \quad$ of the model's output to the measured time series $y(t)$.

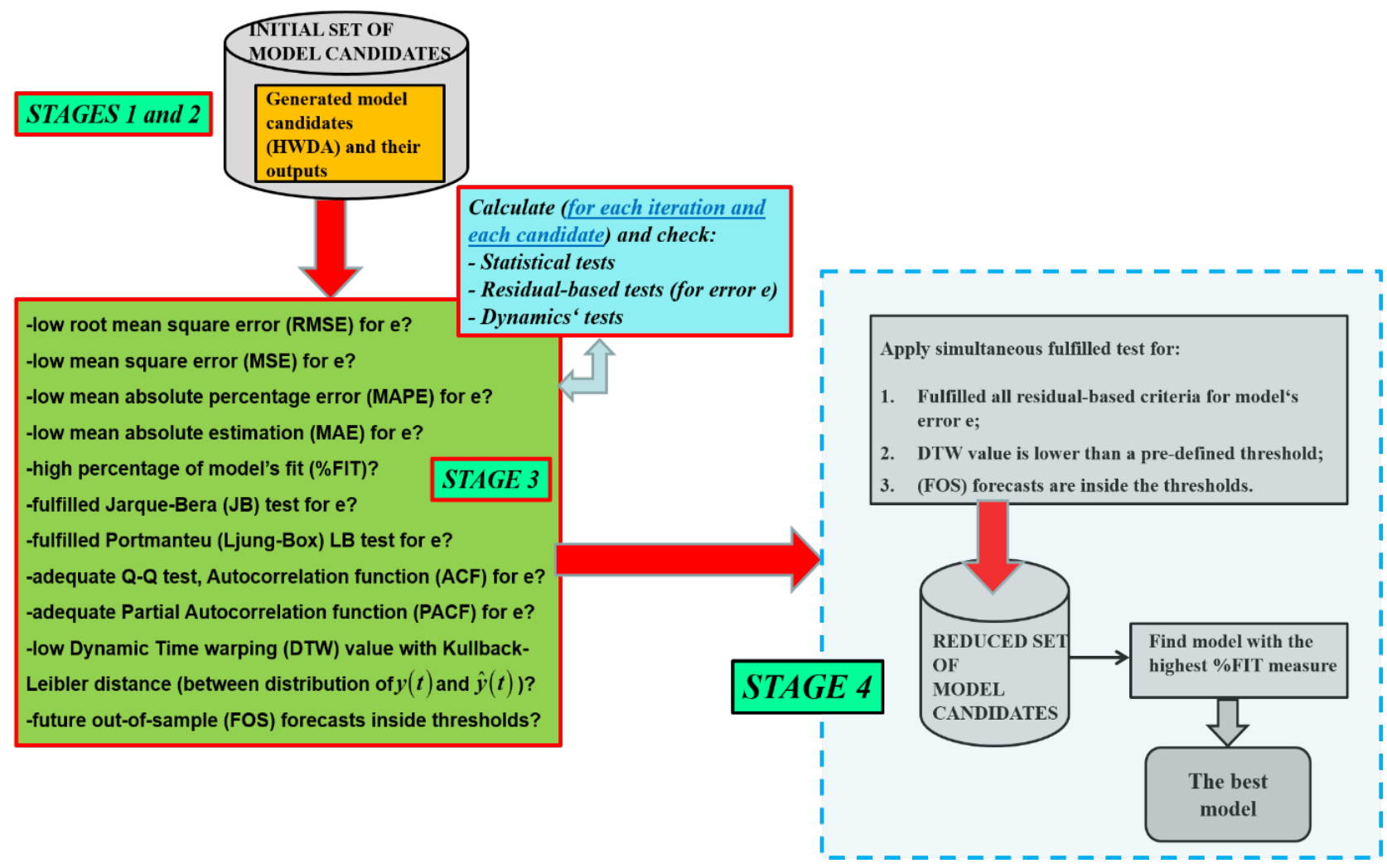

Figure 4. The more in detail illustrated working mecha nism of an applied heuristic for stages 3 and 4 from Fig. 3.

Regarding all observed emor-based and other criteria, of which some are not depicted in Fig. 4, the following set of expressions can be given for each iteration $\mathrm{j}$ [63-66]:

$$
\begin{aligned}
& \operatorname{MSE}(j)=\frac{1}{n} \cdot \sum_{t=1}^{n} e^{2}(t, j), \quad \operatorname{RMSE}(j)=\sqrt{\operatorname{MSE}(j)}, \quad \operatorname{MAE}(j)=\frac{1}{n} \cdot \sum_{t=1}^{n}|e(t, j)| \\
& \operatorname{MAPE}(j)=\frac{1}{n} \cdot \sum_{t=1}^{n}\left|\frac{e(t, j)}{y(t)}\right| \cdot 100 \quad \max _{-} \operatorname{err}(j)=\max |e(t, j)| \\
& \operatorname{RMSE}_{\text {relative }}(j)=\frac{\operatorname{RMSE}(j)}{\max (y(t))-\min (y(t))} \quad \operatorname{MAE}_{\text {relative }}(j)=\frac{\operatorname{MAE}(j)}{\max (y(t))-\min (y(t))} \\
& \% \operatorname{FIT}(j)=100 \cdot\left[1-\frac{\|y(t)-\hat{y}(t, j)\|}{\|y(t)-\operatorname{mean}(y(t))\|}\right] \\
& \operatorname{DTW}[d(j)]=\operatorname{DTW}\left\{d\left[y, \hat{y}_{j}\right]\right\}=\operatorname{DTW}\left\{\sum_{t=1}^{N}\left[y(t)-\hat{y}_{j}(t)\right] \cdot\left[\log y(t)-\log \hat{y}_{j}(t)\right]\right\}
\end{aligned}
$$

Here, max_er refers to the maximum absolute value of the $e(t, j)$, while $\Delta y=\max (y(t))-\min (y(t))=81167-29647=51520$ (see Fig. 2) reflects the dynamic range of 


\section{Logistic $s \&$ Susta ina ble Transp ort \\ Vol. 10, No. 1, J une 2019, 11-30 \\ doi: $10.2478 /$ jlst-2019-0002}

the $y(t)$. The interested reader can find the exact form of expressions for all other criteria (e.g., J B test, $B$ test, etc.) from Fig. 4 in the appropriate statistics based, time-series based, and econometric s literature.

\section{PRACTICAL NUMERICAL RESULTS}

MATLAB, a technic al computing environment, was deployed in order to calculate all the results. In order to extract the best model, The MATLAB environment was caried out in order to both generate and then identify the HWDA model candidates. Moreover, the Econometrics Toolbox, a long with Machine Leaming \& Statistics Toolbox were considered to camy out the statistical testing and diagnostics of the model candidates. The System identification toolbox was used to derive the benchmarking ARIMA model. In order to merge all parts of the modeling process, MATLAB basic environment was considered.

A. In-Sample estimation and validation results for the best HWDA model

In this section, we discuss about the in-sample estimation and validation results for the best HWDA model, which means the results that are refeming to the estimation and test interval. Fig. 5 depic ts the prediction results for the best HWDA model on those two intervals, as well as forecasts on the future out-of-sample (prediction) interval. In Fig. 5, the comparison between the observed time series $y(t)$ and the estimated forecasts $\hat{y}_{j}(t)_{\text {best }}=\hat{y}\left(t, j^{*}\right)=\hat{y}_{H W D A}\left(t, j^{*}\right)$ for the best model is provided. The separation between the "estimation interval" and the "test interval" is done in order to distinguish between the first 40 observations used to estimate the smoothing parameters $\alpha, \beta, \gamma, \phi$, and 16 observations used for testing the predictive power of the best HWDA model. Also, the benchmarking with the ARIMA model and official forecast for the year 2017 is shown in Fig. 5 (discussed later in the following two sections). As it tums out, the estimated values for the smoothing parameters of the best HWDA model (see 1) are:

$$
\begin{aligned}
& \alpha^{*}=\alpha\left(j^{*}\right)=0.701 \\
& \beta^{*}=\beta\left(j^{*}\right)=0.922 \\
& \gamma^{*}=\gamma\left(j^{*}\right)=0.308 \\
& \phi^{*}=\phi\left(j^{*}\right)=0.971
\end{aligned}
$$

These parameter values were calculated at the "best" iteration $j$, where the following "best" c riteria were simulta neously a c hieved (see Fig. 5): 


$$
\begin{aligned}
& \operatorname{MSE}\left(j^{*}\right)=\frac{1}{N} \cdot \sum_{t=1}^{N} e^{2}\left(t, j^{*}\right)=2.34 \cdot 10^{6}, \quad \operatorname{RMSE}\left(j^{*}\right)=\sqrt{\operatorname{MSE}\left(j^{*}\right)}=1531.3, \\
& \operatorname{MAE}\left(j^{*}\right)=\frac{1}{N} \cdot \sum_{t=1}^{N}\left|e\left(t, j^{*}\right)\right|=1324.7, \quad \operatorname{MAPE}\left(j^{*}\right)=\frac{1}{N} \cdot \sum_{t=1}^{N}\left|\frac{e\left(t, j^{*}\right)}{y(t)}\right| \cdot 100=2.8516 \% \\
& \text { max_err }\left(j^{*}\right)=\max \left|e\left(t, j^{*}\right)\right|=2671.9 \\
& \operatorname{RMSE}_{\text {relative }}\left(j^{*}\right)=\frac{\operatorname{RMSE}\left(j^{*}\right)}{51520}=0.029722 \\
& \operatorname{MAE}_{\text {relative }}\left(j^{*}\right)=\frac{\operatorname{MAE}\left(j^{*}\right)}{51520}=0.025711 \\
& \% \operatorname{FIT}\left(j^{*}\right)=100 \cdot\left[1-\frac{\left\|y(t)-\hat{y}\left(t, j^{*}\right)\right\|}{\| y(t)-\text { mean }(y(t)) \|}\right]=78.66 \% \\
& D T W\left[d\left(j^{*}\right)\right]=D T W\left\{d\left[y, \hat{y}_{j^{*}}\right]\right\}=D T W\left\{\sum_{t=1}^{N}\left[y(t)-\hat{y}_{j^{*}}(t)\right] \cdot\left[\log y(t)-\log \hat{y}_{j^{*}}(t)\right]\right\}=1829.2
\end{aligned}
$$

The results shown in (4) implic ate that a percent of fit $78.66 \%$ to the real data was failly good (c.f. Fig. 5). Also, the output of the best model has never shown some more serious deviations from the real data, since $\operatorname{MAPE}\left(j^{*}\right)=2.8516 \%$ was quite small, i.e., far below $10 \%$, which is usually an acceptable threshold suggested by many researchers, (e.g., [흐, 68]). Furthermore, the measures $R M S E_{\text {relative }}\left(j^{*}\right)=0.029722$, and $\operatorname{MAE}_{\text {relative }}\left(j^{*}\right)=0.025711$ were quite low as well. Even more importantly, from the practical engineening point of view, a maximum error has stayed within $5 \%$ of the maximum dynamic range of the $y(t)$ (i.e., $\max _{-} \operatorname{err}\left(j^{*}\right) / \Delta y=2671.9 / 51520=0.051$ ). Furthemore, as it tumed out, all fulfilled diagnostic emror-based tests (e.g., JB test, LB test, Q-Q test, ACF and PACF test) has shown that the best HWDA model's emor $e\left(t, j^{*}\right)$ a pproximately follows the required properties of the normal white noise.

To conclude, our final HWDA model provides a relatively good fit to the real US tourists' inflow data, although it does not have such sophistic ated working mechanism as some more advanced time-series models (e.g., Box-J enkins family of models [69]. Furthermore, our model does not suffer from any signific ant overfitting and ina dmissible oscillatory behavior at some specific time points as for example the other classical exponential smoothing models, including the basic version of an HWDA model.

It is true that there are some more sophisticated details of the real data dynamics detected that are not covered by our model. We believe that two major rea sons a re responsible for thisfact:

- Firstly, the observed time series seems to conta in a quite complex nature of its dynamics, which could not be captured with our model possessing a relatively simple structure. The stochastic mechanism that generates the time series most likely conta ins certa in signific a nt nonlinea rities, while there might also be some other important extemal effects that have not been modeled. Although such phenomena remain un-modeled, our model still offers a useful tool for forecasting of the major variations in the time series dynamics.

- Secondly, the compendium of all required criteria for the selection of our final model was extremely rigorous, particularly conceming the requirements about model's emor to be white noise, so the best fit to the data was not the only criterion. Nevertheless, despite this, the final model provides a satisfactorily well fit, partic ula rly conceming the ma in trend's movements. 


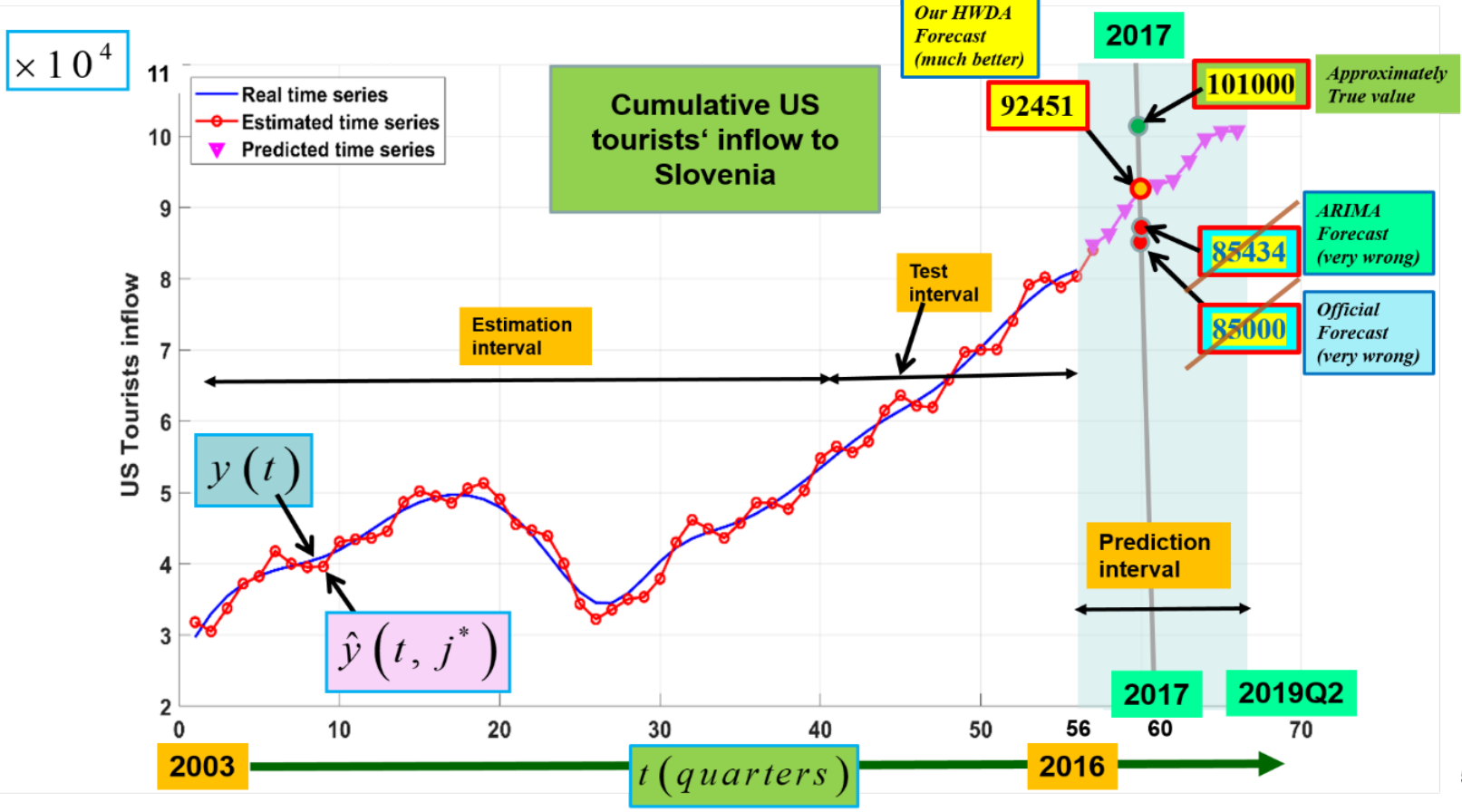

Figure 5 - The prediction results for the best HWDA model and benchmarking with the ARIMA model and official forecast for the year 2017 (estimation, test, and prediction interval).

B. Benchmarking with the ARIMA model and official forec asts on the prediction interval

Table 1 shows the benchmarking results on the prediction interval, i.e., the comparison of our HWDA model with competitive ARIMA model and official forecasts (c.f. also Fig. 5, the year 2017). Here, ten future predicted quarterly values in the period from 2017Q1 to 2019Q 2 are given for the HWDA model and for the ARIMA model. As can be seen from table 1, our HWDA model (value 92451) has at the end of the last quarter of the year 2017 (Q4) by far outperformed the competitive ARIMA model (value 85434) and official forecasts (value approx. 85000) and approached much closer to the real value of approximately $\mathbf{1 0 1 . 1 0 0}$ of US to unists. On the other side, it can be noticed that the forecasts of the ARIMA model possessed a much slower prediction dynamics, i.e., their inc rea sing was far too sluggish.

Table 1. The benchmarking results on the prediction interval (the comparison of the HWDA model with competitive ARIMA model and offic ial forecasts).

\begin{tabular}{|c|c|c|c|c|c|}
\hline Year & Quarter & HMDA & ARIMA & $\begin{array}{c}\text { Official } \\
\text { Forecasts }\end{array}$ & Real value \\
\hline 2017 & Q1 & $\mathbf{8 4 7 3 5}$ & 82372 & $\mathrm{nr}$ & $\mathrm{nr}$ \\
\hline 2017 & Q2 & $\mathbf{8 6 2 7 7}$ & 83511 & $\mathrm{nr}$ & $\mathrm{nr}$ \\
\hline 2017 & Q3 & $\mathbf{8 9 6 4 2}$ & 84528 & $\mathrm{nr}$ & $\mathrm{nr}$ \\
\hline $\mathbf{2 0 1 7}$ & Q4 & $\mathbf{9 2 4 5 1}$ & 85434 & $\begin{array}{c}\text { Approx. } \\
85.000\end{array}$ & $\begin{array}{c}\text { Approx. } \\
\mathbf{1 0 1 . 1 0 0}\end{array}$ \\
\hline 2018 & Q1 & $\mathbf{9 3 1 3 3}$ & 86243 & $\mathrm{nr}$ & $\mathrm{nr}$ \\
\hline 2018 & Q2 & $\mathbf{9 3 8 1 0}$ & 86964 & $\mathrm{nr}$ & $\mathrm{nr}$ \\
\hline 2018 & Q3 & $\mathbf{9 6 5 4 4}$ & 87608 & $\mathrm{nr}$ & $\mathrm{nr}$ \\
\hline 2018 & Q4 & $\mathbf{9 9 6 2 9}$ & 88182 & $\mathrm{nr}$ & $\mathrm{nr}$ \\
\hline 2019 & Q1 & $\mathbf{1 . 0 0 6 2} \cdot \mathbf{1 0}$ & 88694 & $\mathrm{nr}$ & $\mathrm{nr}$ \\
\hline
\end{tabular}




\begin{tabular}{|c|c|c|c|c|c|}
\hline 2019 & $\mathrm{Q} 2$ & $\mathbf{1 . 0 0 7 6} \cdot \mathbf{1 0}^{\mathbf{5}}$ & 89151 & $\mathrm{nr}$ & $\mathrm{nr}$ \\
\hline
\end{tabular}

Regarding the developed ARIMA model, the latter contained the following estimated structure in the form of the transfer function (with the backshift operator $q^{-1}$ and noise $\varepsilon_{y}(t)$ ) [므, 71]:

$$
\begin{aligned}
& A(q) \cdot \Delta \hat{y}_{\text {ARIMA }}(t)=A(q) \cdot\left[\hat{y}_{\text {ARIMA }}(t)-\hat{y}_{\text {ARIMA }}(t-1)\right]=C(q) \cdot \varepsilon_{y}(t) \\
& A(q)=1 \underbrace{-0.89205}_{\left(t\left(a_{1}\right)=-15.61\right)} \cdot q^{-1} \\
& C(q)=1 \underbrace{+0.97}_{\left(t\left(c_{1}\right)=20.011\right)} \cdot q^{-1} \underbrace{+0.9654}_{\left(t\left(c_{2}\right)=35.381\right)} \cdot q^{-2}, \\
& \left|t\left(a_{1}\right)\right|,\left|t\left(c_{1}\right)\right|,\left|t\left(c_{2}\right)\right|>t_{k r i t} \approx 1.97
\end{aligned}
$$

-Residual tests confirm the approx. white noise of model's error

-All zeros and poles of transfer function inside the unit circle

-All $t$ values (in parenthesis) statistically significant

Conceming the methodologies of official forecasts, they are usually never revealed to the public. However, based on source [72], the forec asts in the tourism sectorare usually based on BoxJ enkins fa mily of models, with partic ula remphasis on the ARIMA and similar models.

\section{Out-of-Sample prediction results for the best HWDA model}

Fig. 5 also shows a predictive performance of our model on the future prediction interval from the first quarter of 2017 to the end of the second quarter of 2019, i.e., forecasts $\hat{y}_{j^{*}}(N+h), N=56, h=1,2, \ldots, 10$ quarters for ten quarters ahead (from the end of 2016). The more precise details of this predictive behavior are shown in Fig. 6, where the prediction results for the best HWDA model are enlarged foc using exclusively on a prediction interval.

As we can see from Fig. 5 and 6, our model gives quarterly forecasts $\{84735,86277,89642,92451\}$ tourists for the year 2017, quarterly forecasts $\{93133,93810,96544,99629\}$ tourists for the year 2018, and two forecasts $\left\{1.0062 \cdot 10^{5}, 1.0076 \cdot 10^{5}\right\}$ tourists for the first two quarters of the year 2019.

If we are now firstly focused on the (end of the) year 2017 (c.f. Fig. 5), we can clearly see that our model has predicted the value 92451, while we have seen before that the competitive ARIMA model and the offic ial institutions have predicted signific antly under-estimated values. Thus, our model was able to much more precisely identify the amplified rising trend of the influx's dynamics than it was predic ted from the side of the Slovenian official institutions.

However, it has in rough terms predicted the true value with a time delay of about one year (c.f. the last two forecasts $\left\{1.0062 \cdot 10^{5}, 1.0076 \cdot 10^{5}\right\}$ ). Furthermore, the role of the possible future new crisis cannot be ignored and there might be a declining trend as well. Namely, sumprisingly, the scope of the predicted trend seems to decline if looking at the last three forecasts $\left\{99629,1.0062 \cdot 10^{5}, 1.0076 \cdot 10^{5}\right\}$.

Thus, the implications of the forecasts for the forthcoming years till the end of the year 2019 or later can seriously womy us. Maybe we can even conclude that there exists certa in possibility that some substantial (global?) negative macroeconomic behavior will happen again in the near future, perhaps in the US and/or the EU, or worse, worldwide. These fears can also be detected 
from several other works (such as [73-75], where scholars emphasize scares about new approaching dangerous economic events.

Namely, in a couple of studies, a new economic stagnation or recession is forecasted somewhere in the period 2019-2020 [74, 76], while some academics even wam about an outbreak of the new global economic crisis [75]. Their expectations a re based on various a nalyses such as for example "what if" scenario playing analysis [푸, 므], where China's declining economic performance represents the biggest concem. The latter is even amplified after the enuption of serious economic war that was initiated by the USA recently aga inst some other countries, where China seems to be a primary target [ㄱ].

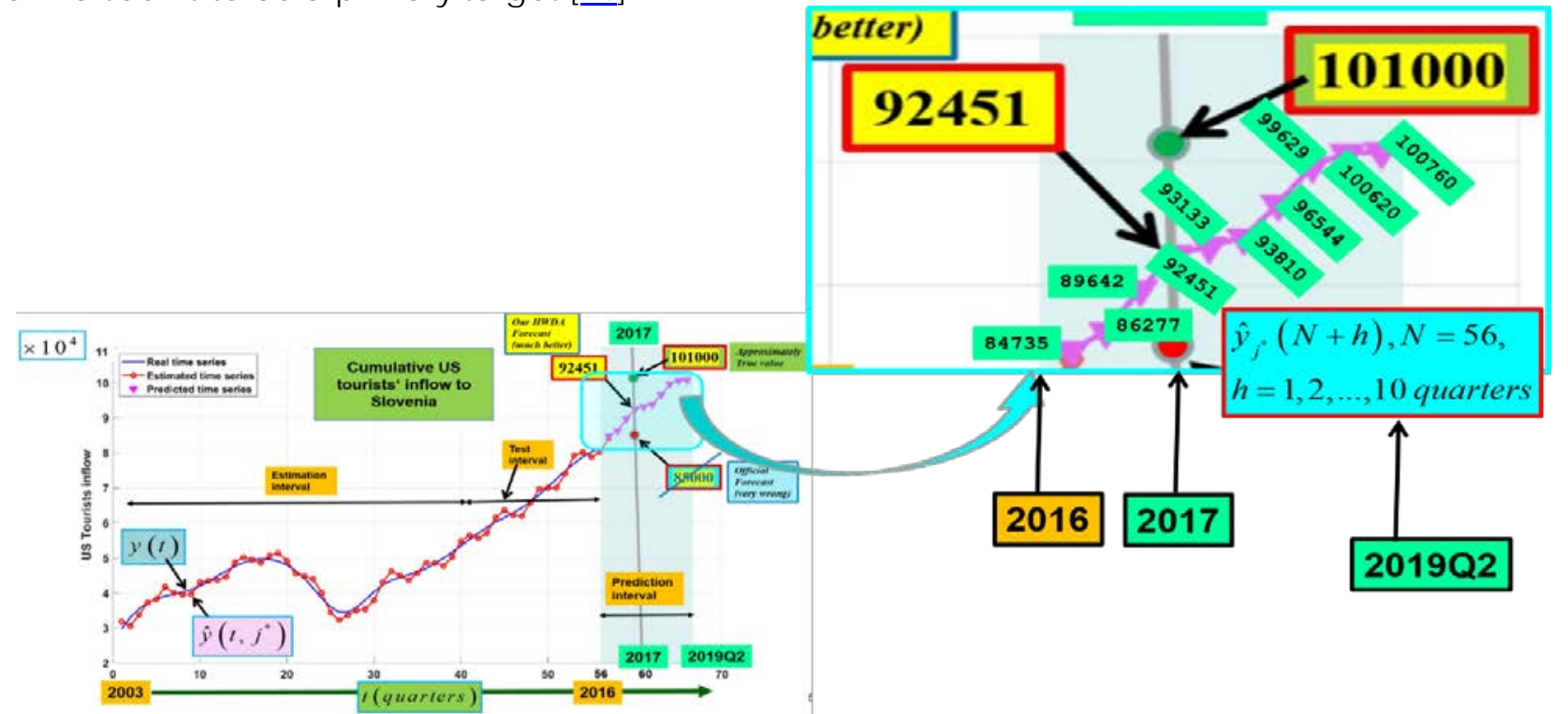

Figure 6 - The prediction results for the best HWDA model (enlarged details of the prediction interval).

D. Main findings and implications of the study

Based on the results of this study, we can express some main findings and implications. The fact is that we have designed a modified working HWDA model driven by additional specially designed heuristics that helped to overcome the deficiencies of relatively simple exponential smoothing structure.

Our model has significantly outperfomed the competitive ARIMA model and official forecasts for the year 2017, a lthough the latter a re usually based on much more complex models. We might have expected that this cannot be possible. Namely, due to [77], in times of the last economic crisis, the global nature of the time series has become much more complex with a mplified volatility. Consequently, since then, more sophisticated forecasting models are needed to incorporate a bigger complexity of the time series, as models with a simpler structure are not good enough anymore.

Thus, we cannot ima gine the reason why the official models have completely failed. Maybe there was some kind of misinterpretation of results or misuse of the models? Nevertheless, it was confimed again that in general, we should not have blindly followed official prognosis with a hundred percent trust.

Namely, the fact is that our model managed to capture a $19.8 \%$ increase in the tourists' inflow in 2017 much more precisely than the competitive forecasters. Furthemore, we are aware that we have mentioned only indirect assumptions that such large increase of the US tourists' inflow in such short time has happened also due to an important influence of Melanie Trump on US citizens.

But whatever the reason would be, the contributions in this paper related to the methodological novelties of the designed HWDA model with a failly good forecasting capability cannot be neglected. Moreover, this study was by our best knowledge the first in-depth attempt of 
research after longer time-period that have tried to improve the capabilities of the basic HWDA model. Fairly good forecasting results were achieved despite the fact that the predictions were based only on the historic al data of the targeted inflow time series.

Thus, the model was derived without screening the other time series, e.g. those reflecting the US economy (macroeconomic indic ators), as the Box-J enkins ARIMAX and other similar models are capable of administering [14-16, 69]. In the future work, we intend to somehow incorporate more concrete quantification of Melanie's influence on the US tounists' behavior, maybe by integrating of additional time series reflecting the time-dependent percentage level of her popula rity a mong US citizens.

Moreover, to make such quantitative research even more credible, it is also planned to apply a questionnaire-based survey among the US tourists in Slovenia in order to identify the truly main reasons for their visiting of Slovenia. Also, we are planning to engage the US macroeconomic indic ators' time series by means of ARIMAX and other more sophistic ated models that can involve the exogenous inputs, as well as intervention and other hidden effects in the time series. By simultaneously using additional variables in the model and adopting of similar heuristics as were presented in this paper, we expect to achieve even more adequate predictive behavior.

\section{CONCLUSION}

In the paper, we have developed a forecasting module to predict the cumulative inflow of US tourists to Slovenia. The modeling framework was designed in such a way that the classical HoltWinters Damped model was upgraded with special heuristics to improve the forecasts of its basic exponential smoothing model's counterpart. In the modeling procedure, a sequence of carefully selected and categorized rigor criteria was adopted to find the best model among the large group of model candidates.

The derived best model has achieved fairly accurate prediction results, particularly regarding the main trend's movements. As it tumed out for In-Sample interval, it achieved even a $78.66 \%$ fit to the real-time series data, while the largest model's error did not exceed the $5 \%$ of the dynamic range of the observed time series. Regarding the Out-of-Sample Interval, our model has predicted 92451tourists for the end of 2017, while the ARIMA model and official forecasts have achieved much worse results, i.e. 85434 and 85000 tourists, respectively. Thus, our model has signific antly outperformed the competitive ARIMA model and official forecasts and have got much closer to the real value of a bout 101000 tourists.

Besides the methodological issues, the particular emphasis was dedicated to the discussion about the American tourists, and presumably the important role Melanie Trump has had regarding an inflow's increase of even $19.8 \%$ of the tounists in just one year. However, the implic it or explic it linkage between growth in tourism inflow and Melanie Trump were emphasized to be outside this paper's study scope. Indeed, we emphasized that any periodic al socio-politic al alterations across a globe may substantially influence all interconnected globally economic ecosystems including tourism due to advancements in Information Technology, Transportation infrastructure, mass media, etc.

The study has also debated about a growing role that the US tourists have within the scope of Slovenian tourism. Thus, particular attention should be needed to keep persisting doing on enforced tourism marketing to attract even more American tourists. Namely, they are known as greeted tourists and large consumers spending a lot of personal finances to discover all the natural and other bea uties that Slovenia can offer to them.

\section{REFERENCES}

[1] www.slovenia.info. (2016). I Feel Slovenia

[2] N. Kovačić, D. Topolšek, and D. Dragan, "Tourism sector, Travel agencies, and Transport Suppliers: Comparison of Different Estimators in the Structural Equation Modeling," Logistics \& Sustainable Transport, vol. 6, no. 1, pp. 11-24, 2015. 
[3] R. Hyndman, A. B. Koehler, J. K. Ord, and R. D. Snyder, Forecasting with exponential smoothing: the state space approach. New York: Springer Science \& Business Media, 2008.

[4] A. Gosar, "Some Characteristic s of Tourism in Slovenia," Slovene Studies J oumal, vol. 12, no. 1, pp. 3342, 1990.

[5] M. Konecnik and F. Go, "Tourism destination brand identity: The case of Slovenia," Joumal of Brand Mana gement, vol. 15, no. 3, pp. 177-189, 2008.

[6] A. Assaf and K. L. Cvelbar, "Privatization, market competition, intemational attractiveness, management tenure and hotel perfomance: Evidence from Slovenia," Intemational Joumal of Hospitality Management, vol. 30, no. 2, pp. 391-397, 2011.

[7] T. Mihalič, V. Žabkar, and L. K. Cvelbar, "A hotel sustainability business model: evidence from Slovenia," J oumal of Sustainable Tourism, vol. 20, no. 5, pp. 701-719, 2012.

[8] V. Žabkar, M. M. Brenčič, and T. Dmitrović, "Modelling perceived quality, visitor satisfaction and behavioural intentions at the destination level," Tourism management, vol. 31, no. 4, pp. 537-546, 2010.

[9] SSD, "Slovene: Statistični Urad Republike Slovenije," Statistični Urad Republike Slovenije, https:// www.stat.si/statweb2016.

[10] J. W. Taylor, "Exponential smoothing with a damped multiplicative trend," Intemational joumal of Forecasting, vol. 19, no. 4, pp. 715-725, 2003.

[11] R. C. Souza, M. Barros, and C. V. C. d. Miranda, "Short Term Load Forecasting Using Double Seasonal Exponential Smoothing and Interventions to Account for Holidays and Temperature Effects," presented at the TLAIO II-2 do Taller Latino Iberoamericano de Investigación de Operaciones, Acapulco, Méxic o., 2007.

[12] J. Taylor, "Short-Tem Electricity Demand Forecasting Using Double Seasonal Exponential Smoothing," J oumal of Operational Research Society, vol. 54, pp. 799-805, 2003.

[13] J. Taylor, L. Menezes, and P. McShamy, "A Comparison of Univariate Methods for Forec asting Eletric ity Demand up to a Day Ahead,"Intemational J oumal of Forecasting, vol. 22, no. 1, pp. 1-16, 2006.

[14] M. Intihar, T. Kramberger, and D. Dragan, "The relationship between the economic indicators and the accuracy of container throughput forecasting," in IAME 2015 Conference Kuala Lumpur, Malaysia, Kuala Lumpur, 2015

[15] M. Intihar, T. Kramberger, and D. Dragan, "Container Throughput Forecasting Using Dynamic Factor Analysis and ARIMAX Model," Promet-Traffic Transportation, vol. 29, no. 5, pp. 529-542, 2017.

[16] D. Dragan, T. Kramberger, A. Lisec, and M. Intihar, "The Impact of Macroeconomic Indicators on Forecasting a Total Cargo Throughput in the Adriatic Seaport," in Symposium on Logistic S (ISL 2017) Data Driven Supply Chains, 2017.

[17] D. N. Aratuo and X. L. Etienne, "Industry level analysis of to urism-economic growth in the United States," Tourism Management, vol. 70, pp. 333-340, 2019.

[18] WEF, The travel and tourism competitiveness report 2015. World Economic Forum, 2015.

[19] J. Balaguer and Cantavella-J orda, "Tourism as a long-run economic growth factor: the Spanish case," Applied economic s, vol. 34, no. 7, pp. 877-884, 2002.

[20] A. Lanza, P. Temple, and G. Urga, "The implications of tourism specialisation in the long run: an econometric analysis for 13 OECD economies," Tourism Mana gement, vol. 24, no. 3, pp. 315-321, 2003.

[21] J. G. Brida, B. Lanzilotta, S. Lionetti, and W. A. Risso, "Research note: The to urism-led growth hypothesis for Unuguay,"J oumal of Polic y Research in Tourism, Leisure, vol. 16, no. 3, pp. 765-771, 2010.

[22] N. Dritsakis, "Tourism development and economic growth in seven Mediteranean countries: A panel data approach," Tourism Economics, vol. 18, no. 4, pp. 801-816, 2012.

[23] M. d. P. Pablo-Romero and J. A. Molina, "Tourism and economic growth: A review of empinical literature," Tourism Management Perspectives, vol. 8, pp. 28-41, 2013.

[24] L. Gunduz and A. Hatemi-J, "Is the tourism-led growth hypothesis valid for Turkey?," Applied Economics Letters, vol. 12, no. 8, pp. 499-504, 2005.

[25] M. Belloumi, "The relationship between tourism receipts, real effective exc hange rate and economic growth in Tunisia," Intemational joumal of to unism research, vol. 12, no. 5, pp. 550-560, 2010.

[26] S. Proença and E. Soukiazis, "Tourism as an economic growth factor: a case study for Southem European countries," Tourism Economics, vol. 14, no. 4, pp. 791-806, 2008.

[27] S. Katircioğlu, "Research note: Testing the tourism-led growth hypothesis for Singapore-an empinical investigation from bounds test to cointegration and Granger causality tests," Tourism Economic s, vol. 16, no. 4, pp. 1095-1101, 2010.

[28] J.G. Brida, W. A. Risso, and Events, "Tourism as a determinant of long-run ec onomic growth,"J oumal of Policy Research in Tourism, Leisure, vol. 2, no. 1, pp. 14-28, 2010.

[29] D. Dragan, A. Keshavarzsaleh, B. Jereb, and D. Topolšek, "Integration with transport suppliers and efficiency of travel agencies," Intemational Joumal of Value Chain Management, vol. 9, no. 2, pp. 122-148, 2018.

[30] M.-H. Chen, 'Interactions between business conditions and financial perfomance of tourism fims: Evidence from China and Taiwan," Tourism Management, vol. 28, no. 1, pp. 188-203, 2007. 
[31] R. C. Mill and A. M. Morrison, The tourism system. Dubuque: Kendall Hunt, 2002.

[32] C.-H. H. Tang and S. S. Jang, "The tourism-economy causality in the United States: A sub-industry level examination," Tourism Management, vol. 30, no. 4, pp. 553-558, 2009.

[33] A. K. Adebayo and A. C. Iweka, "Optimizing the sustainability of tourism infrastructure in Nigeria through design for deconstruction framework," Americ an J oumal of Tourism Management, vol. 3, no. 1A, pp. 13-19, 2014.

[34] B. Zheng and Y. Zhang, "Household expenditures for leisure tourism in the USA, 1996 and 2006," Intemational J oumal of Tourism Research, vol. 15, no. 2, pp. 197-208, 2013.

[35] J. Khadaroo and B. Seetanah, "Transport infrastructure and tourism development," Annals of tourism research, vol. 34, no. 4, pp. 1021-1032, 2007.

[36] K. M. Cheng, "Tourism demand in Hong Kong: Income, prices, and visa restric tions," Current Issues in Tourism, vol. 15, no. 3, pp. 167-181, 2012.

[37] J. N. Goodrich, "September 11, 2001 Attack on Americ a: Impact on Tourism Sec urity," J oumal of Tra vel Tourism Marketing, vol. 11, no. 4, pp. 1-12, 2002.

[38] I. Chatziantoniou, S. Degiannakis, B. Eeckels, and G. Filis, "Forecasting tourist a miva ls using origin country macroec onomic s," Applied Economics, vol. 48, no. 27, pp. 2571-2585, 2016.

[39] C. L Morley, "A microeconomic theory of intemational tourism demand," Annals of Tourism Research, vol. 19, no. 2, pp. 250-267, 1992.

[40] F. Chan and C. Lim, "Spectral analysis of sea sonality in tourism demand," Mathematic s Computers in Simulation, vol. 81, no. 7, pp. 1409-1418, 2011.

[41] D. Gounopoulos, D. Petmezas, and D. Santamaria, "Forecasting tourist arivals in Greece and the impact of macroeconomic shocks from the countries of tourists' origin," Annals of Tourism Research, vol. 39, no. 2, pp. 641-666, 2012.

[42] V.J.T. m. Cho, "A comparison of three different approaches to tourist arival forecasting," vol. 24 , no. 3, pp. 323-330, 2003.

[43] F.-L Chu, "A fractionally integrated autoregressive moving a verage approach to forecasting tourism demand," Tourism Management, vol. 29, no. 1, pp. 79-88, 2008.

[44] F.-L Chu, "A piecewise linear approach to modeling and forecasting demand for Macau tourism," Tourism Management, vol. 32, no. 6, pp. 1414-1420, 2011.

[45] H. Song, G. Li, S. F. Witt, and G. Athanasopoulos, "Forecasting tourist a mivals using time-varying parameter structural time series models," Intemational J oumal of Forecasting, vol. 27, no. 3, pp. 855869, 2011.

[46] H. Hassani, A. Webster, E. S. Silva, and S. Heravi, "Forecasting US tourist a miva ls using optimal singular spectrum a na lysis," Tourism Mana gement, vol. 46, pp. 322-335, 2015.

[47] B. Peng, H. Song, and G. Crouch, "A meta-analysis of intemational tourism demand forec asting and implic ations for practice," Tourism Mana gement, vol. 45, pp. 181-193, 2014.

[48] S. F. Witt, H. Song, and G. Li, The advanced ec onometrics of tourism demand. Abingdon: Routledge, 2008.

[49] M. Akal, "Forec asting Turkey's tourism revenues by ARMAX model," Tourism Ma nagement, vol. 25, no. 5, pp. 565-580, 2004.

[50] C. Lim, M. McAleer, and J. C. Min, "ARMAX modelling of intemational tounism dema nd," Mathematic S Computers in Simulation, vol. 79, no. 9, pp. 2879-2888, 2009.

[51] H. Grubb and A. Mason, "Long lead-time forecasting of UK a ir passengers by Holt-Winters methods with damped trend," Intemational J oumal of Forecasting, vol. 17, no. 1, pp. 71-82, 2001.

[52] G. Athanasopoulos and A. de Silva, "Multivariate exponential smoothing for forecasting to urist a mivals," J oumal of Tra vel Research, vol. 51, no. 5, pp. 640-652, 2012.

[53] P. Dimitrov, M. Kalinova, G. Gantchev, and C. Nikolov, "Exponential forec asting of the monthly volume of the to urism rec eipts in Bulga ria," Tourism Mana gement Studies, vol. 11, no. 1, pp. 104-110, 2015.

[54] D. O. Gomezelj and T. Mihalič, "Destination competitiveness-Applying different models, the case of Slovenia," Tourism management, vol. 29, no. 2, pp. 294-307, 2008.

[55] T.-. SURS, Annual Report on Tourism 2015 - Slovenia (National a nnual reports on tourism). Ljublja na: Statistic al Office of the Republic of Slovenia, 2015.

[56] T. W. T. T. C. (WTTC), Travel \& Tourism: Economic Impact 2015-Slovenia London: The World Travel \& Tourism Council (WTTC), 2015.

[57] R. J. Hyndman, A. B. Koehler, R. D. Snyder, and S. Grose, "A state space framework for a utomatic forecasting using exponential smoothing methods," Intemational Joumal of forecasting, vol. 18, no. 3, pp. 439-454, 2002.

[58] R. J. Hyndman and A. B. Koehler, "Another look at measures of forecast accuracy," Intemational joumal of forecasting, vol. 22, no. 4, pp. 679-688, 2006.

[59] L. F. Tratar, B. Mojškerc, and A. Toman, "Demand forecasting with four-parameter exponential smoothing," Intemational J oumal of Production Ec onomics, vol. 181, pp. 162-173, 2016. 
[60] E. S. GardnerJ r and E. McKenzie, "Forecasting trends in time series," Management Science, vol. 31, no. 10, pp. 1237-1246, 1985.

[61] E. S. Gardner Jr and E. McKenzie, "Note-Seasonal exponential smoothing with damped trends," Management Science, vol. 35, no. 3, pp. 372-376, 1989.

[62] H. B. Mitchell, Data fusion: concepts and ideas. New York: Springer Science \& Business Media, 2012.

[63] J. Sueur, Sound Ana lysis and Synthesis with R. Ba sel: Springer 2018.

[64] John E. Hanke and D. Wichem, Business Forecasting: Pearson New Intemational Edition (9e). Melboume: Pearson Australia Group Pty Ltd, 2013.

[65] Bruce L. Bowerman, Richard O'Connell, and A. Koehler, Forecasting, Time Series, and Regression London: Cengage Leaming, 2005.

[66] D. Dragan, T. Kramberger, and M. Intihar, "A comparison of Methods for Forecasting the Container Throughput in North Adria tic Ports," in Conference IAME, Norfolk, 2014.

[67] J. A. D. Jennifer L. Castle and F. H. David, Some forecasting principles from the M4 competition. Magdelen College and Nuffield College, 2019.

[68] S. Makridakis, E. Spiliotis, and V. Assimakopoulos, "The M4 Competition: Results, findings, c onc lusion and way forwa rd," Intemational J oumal of Forecasting ·, vol. 34, no. 4, pp. 802-808, 2018.

[69] G. E. Box, G. M. J enkins, G. C. Reinsel, and G. M. Ljung, Time series a nalysis: forecasting and control. New York: J ohn Wiley \& Sons, 2015.

[70] L. Ljung, System identific ation: theory for the user. Upper Saddle River, New J ersey: Prentic e-Hall, 1987, pp. 519-519.

[71] L. Ljung, System Identific ation Toolbox for use with MATLAB. Nattick: Mathworks, 2011.

[72] S. Gričar and Š. Bojnec, Aplikacija metodologije časovnih serij na primeru turističnih cen. Koper: Založba Univerze na Primorskem, 2016.

[73] R. Powell, "Risk scenarios," in "Asia Regional Strategic Forecast: Preparing For The Paradigm Shift. Globalisation and the Asian business environment: The Economist Corporate Network Risk scenarios," The Ec onomist Corporate Network. , So uthEa st Asia 2017.

[74] N. Rahman, M. Muridan, and A. Najib, "A Maritime Forecasting Method for Analysing the Total Cargo Handling at Johor Port Berhad from 2013 to 2020," Intemational Joumal of Business Management Economic Research, vol. 6, no. 3, pp. 187-93, 2015.

[75] L. Hsieh, "Roots of the next financial crisis.," ed. Reuters: Reuters, 2017.

[76] W. Buiter, E. Rahbari, M. Saunders, S. Luna, J. Hale, and G. Menuet, Is China leading the world into recession (Global Ec onomic Views, Citi Research). New York,: Citigroup Global Markets Inc. , 2015.

[77] G. Xie, S. Wang, Y. Zhao, and K. K. Lai, "Hybrid approaches based on LSSVR model for container throughput forecasting: a comparative study," Applied Soft Computing, vol. 13, no. 5, pp. 2232-2241, 2013.

\section{AUTHORS}

A. Dejan Dragan, Ph.D., is the Assoc ia te Professor at the Fa c ulty of Logistics, University of Maribor, Celje, Slovenia (e-mail: dejan.dragan@um.si).

B. Abolfaz Keshavarzsaleh, M.Sc., M.Sc., is the Teaching and Research Assista nt at the University of Malaya (UM) and Intemational University of Malaya-Wales (IUMW), Kuala Lampur, Malesya (e-mail: a bolfazl.kesha varz.sa leh@gmail.com).

C. Tomaž Kramberger, Ph.D., is the Associate Professor at the Faculty of Logistic S, University of Maribor, Celje, Slovenia (e-mail: tomaz.kramberger@um.si).

D. Bonut J ereb, Ph.D., is the Associate Professor at the Fac ulty of Logistics, University of Maribor, Celje, Slovenia (e-mail: borut.jereb@um.si).

E. Maja Rosi, Ph.D., is the Tea ching Assista nt at the Fa c ulty of Logistics, University of Ma rib or, Celje, Slovenia (e-mail: maja.rosi@um.si).

Manusc ript received by 12 April 2019.

Published as submitted by the author(s). 